Saudi Journal of Biomedical Research

Abbreviated Key Title: Saudi J Biomed Res ISSN 2518-3214 (Print) |ISSN 2518-3222 (Online)

\title{
Cross-Sectional Study of Prevalence of Genu Varum in Children 6-10 Years of Age in Urhobo, Delta State, Southern Nigeria
}

\author{
Peter D. Okoh ${ }^{1 *}$, John N. Paul ${ }^{2}$, Emmanuel Tobore ${ }^{2}$
}

${ }^{1}$ Department of Surgery, Faculty of Clinical Sciences, College of Health Sciences, University of Port Harcourt, Nigeria

${ }^{2}$ Department of Anatomy, Faculty of Basic Medical Sciences, College of Health Sciences, University of Port Harcourt, Nigeria

DOI: $10.36348 /$ sjbr.2020.v05i03.005

| Received: 23.02.2020 | Accepted: 13.03.2020 | Published: 21.03.2020

*Corresponding author: Peter D. Okoh

\section{Abstract}

Background: Genu varum (bow leg) is a deformity of the knee marked by medial angulations of the leg in relation to the thigh, an outward bowing of the legs, giving the appearance of a bow. This study was carried out to determine the prevalence of genu varum among children between 6-10 years old in some Urhobo communities in Delta state, Southern Nigeria. Materials and Methods: The study populations were drawn by purposive sampling from Ughelli, Warri, and Sapele. Data were collected on 1000 children (500 males and 500 females). Physical examination of the children was carried out by measuring their medial intercondylar distances by using calipers and meter rule while the children stood erect with their ankles touching. Children with medial intercondylar distances greater than $0.2 \mathrm{~cm}$ (the mean value for normal Nigeria children) demonstrates the deformity (genu varum) and the frequency, age. sex was recorded. Results and Discussions: Based on this data, 43 in 1000 volunteers had genu varum. It was also seen that the prevalence was highest in 6 years old age group and lowest in 10 years old age group. It was noted as the ages increase, the prevalence rates among the age groups decreases. The prevalence of this deformity in Urhobo communities is low when compared with the overall prevalence in Nigeria. The Urhobos live in the riverine area of Southern Nigeria and their occupation are mainly farming, hunting and fishing. Their meals consists mainly of products from the farm, hunting and sea foods which are very rich in protein/calcium. Children in Urhobo Communities are also well exposed to sunlight. Conclusion: The prevalence of this genu varum in this ethnic nationality although low can be further reduced with enlightenment and education of parents and children on the importance of balanced diet.

Keywords: Prevalence, Genu varum, Children, Urhobo, Delta State.

Copyright @ 2020: This is an open-access article distributed under the terms of the Creative Commons Attribution license which permits unrestricted use, distribution, and reproduction in any medium for non-commercial use (NonCommercial, or CC-BY-NC) provided the original author and source are credited.

\section{INTRODUCTION}

Genu varum is a Latin term used to describe bow legs [1]. This condition may present from infancy through adulthood and has a wide variety of causes. As it becomes more severe, the patient may exhibit lateral knee thrust and a waddling gait. There may be associated in-toeing and secondary effects on the hip and ankle. Its aetiology is both physiologic and pathologic. It poses a source of concern for the parents. In physiologic genu varum, the condition is selflimiting and usually it needs just clinical follow up. In pathologic cases progression of the condition with time is often the case predisposing to mechanical lower limb problems as well as joint complications. In the physiologic variety, it is important to establish the diagnosis so as to avoid unnecessary treatment. In this study the aetiologic factors affecting the incidence of this condition were assessed. The purpose behind the study is to clarify the aetiologic contribution of various conditions involved so as to base the subsequent management on solid ground [2-4].

Previous studies point to the fact that the physiologic type is still the commonest in our locality. The second commonest cause was found to be nutritional rickets while other causes were uncommon or even extremely rare. These results are contrary to the common local belief that most of the cases in our locality are due to rickets $[4,5]$

Physiologic bowing, which is seen most often, has a well-documented favorable natural history. And is relatively common in children. Idiopathic tibia vara is the most common of the pathologic conditions that are associated with bowed legs; treatment strategies vary with the patient's age and the stage of disease and deformity. Genu varum may also accompany systemic conditions, such as achondroplasia, vitamin D-resistant 
rickets, renal osteodystrophy, and osteogenesis imperfecta-all of which can result in short stature [58].

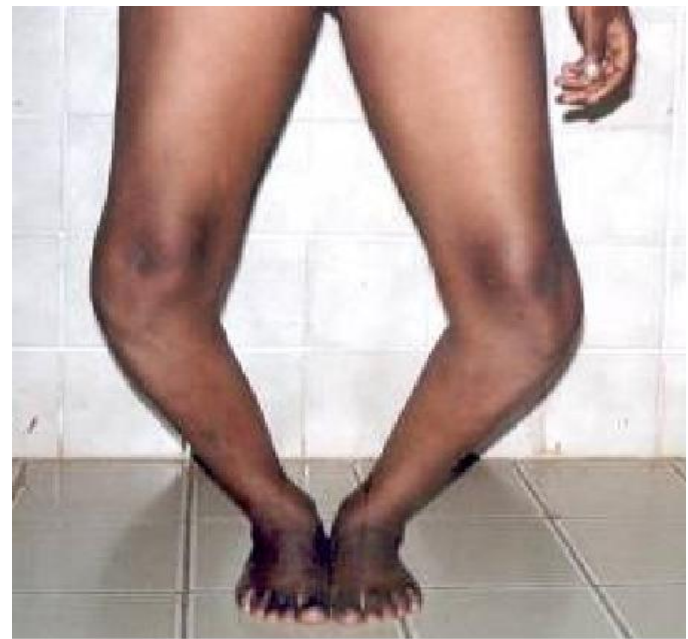

Fig-1: Bilateral recurrent genu varum [2]

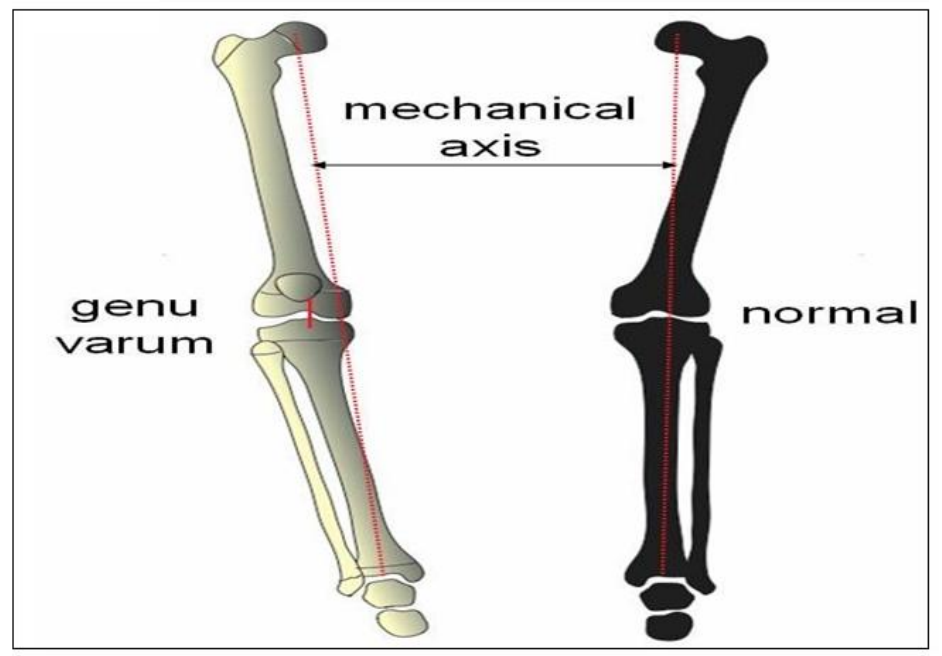

Fig-2: Showing genu varum and a normal condition [1]

It has also been claimed that genu varum deformity would tend to cause an increase in subtalar pronation moment during the contact and also in the propulsion phases of walking, while a genu valgum deformity may cause some increase in subtalar pronation moment during the contact phase and an increase in subtalar supination moment during the early propulsive phase $[9,10]$.

Studies have shown that genu varum can be considered as an effective factor on vertical ground reaction force (as predictor factor of musculoskeletal injuries among the Karate professionals, and backward walking can cause a change in vertical ground reaction force more than forward walking does [10-13].

Indications for intervention are not always well defined. A rare disorder, focal fibrocartilaginous dysplasia, usually requires no treatment. Standing radiographs of the entire lower limbs are necessary for surgical planning, as the deformity can sometimes affect the distal femur rather than the proximal tibia. Restoration of the mechanical axis of the limb is the principal goal of treatment; the particular type of internal fixation is of secondary importance [14-16].

Some researchers have done works related to genu varum and its complications in other populations [4-21].

Most of the studies that have been done on genu varum where on Caucasians and very little is known of its prevalence in local indigenous populations especially in Nigeria. The study of local prevalence will help keep accurate data of this condition and possible remedy where the need arises. This information will therefore, be useful to epidemiologist, orthopaedic surgeons, anatomists and anthropologist.

This study was done to know the prevalence of genu varum in indigenous population as Urhobo ethnic group in Southern Nigeria. 


\section{MATERIALS AND METHOD}

A total population of 1000 volunteers were recruited for the study with 500 males and 500 females with age ranging from 6-10 years residing in Ughelli, Warri and Sapele all in Delta state, Southern Nigeria. The volunteers were recruited with the consent of parents or guardian by signing a consent form on behalf of their wards. The volunteers were recruited by purposive sampling from primary schools, churches and homes. The ages of the volunteers were given by the parents or guardian.

The volunteers were asked to stand erect with their feet together and their ankles touching each other. Then their medial intercondylar distance was measured.

If the medial intercondylar distance is widely apart or beyond the mean value $(0.2 \mathrm{~cm})$ of medial intercondylar distance for Nigeria children [20], then they exhibit the lower limb deformity; genu varum (bow leg).

Some precautionary measures were taken to ensure that the data was captured following the standard procedure. The measurements were taken from the medial intercondylar distance of the knee with the volunteers standing erect and the ankles touching. No volunteer was measured and recorded more than once. Under age volunteers were not recruited for the study.

Statistical analysis of the study was done using summary descriptive statistics in SPSS version 21.

\section{RESULTS}

In Table-1, the males within 6 years of age had the highest prevalence $10(31.3 \%)$ and the least prevalence was seen in age 10 .

Table-1: Frequency table for male sample population

\begin{tabular}{|l|l|l|l|}
\hline Age (years) & Number of subjects & Genu varum frequency & Percentage (\%) \\
\hline 6 & 100 & 10 & 10.0 \\
\hline 7 & 100 & 8 & 8.0 \\
\hline 8 & 100 & 6 & 6.0 \\
\hline 9 & 100 & 5 & 5.0 \\
\hline 10 & 100 & 3 & 3.0 \\
\hline Total & 500 & 32 & 6.4 \\
\hline
\end{tabular}

In Table 2, the females with age bracket 6-7 years had the highest prevalence while the least frequency was seen in age 10 .

Table-2: Frequency table for female sample population

\begin{tabular}{|l|l|l|l|}
\hline Age (years) & Number of subjects & Genu varum frequency & Percentage (\%) \\
\hline 6 & 100 & 3 & 3.0 \\
\hline 7 & 100 & 3 & 3.0 \\
\hline 8 & 100 & 2 & 2.0 \\
\hline 9 & 100 & 2 & 2.0 \\
\hline 10 & 100 & 1 & 1.0 \\
\hline Total & 500 & 11 & 2.2 \\
\hline
\end{tabular}
in age 10 .

In Table-3, the total population had the highest frequency of $30.2 \%$ in age 6 , while the least frequency was seen

Table 3: Frequency table for total sample population

\begin{tabular}{|l|l|l|l|}
\hline Age (Years) & Number of Subjects & Genu Varum Frequency & Percentage (\%) \\
\hline 6 & 200 & 13 & 6.5 \\
\hline 7 & 200 & 11 & 5.5 \\
\hline 8 & 200 & 8 & 4.0 \\
\hline 9 & 200 & 7 & 3.5 \\
\hline 10 & 200 & 4 & 2.0 \\
\hline Total & 1000 & 43 & 4.3 \\
\hline
\end{tabular}

\section{DISCUSSION}

The percentage $(\%)$ prevalence of genu varum (bow leg) in Urhobo communities in Delta state has an average of $4.3 \%$ (43 cases in 1000 sample size). $6.4 \%$ in males and $2.2 \%$ in females. The prevalence of this deformity is higher in males than females which agrees with the research carried out by Mahmoud KarimiMobarake et al., [20] on the prevalence of genu varum in Iranian primary school children. 
It was also noted from the table, that in both sexes, the percentage (\%) of the prevalence of genu varum was highest among children in the age group 6 years and lowest in children at age group 10 years which agrees with the research carried out by Karim et al., [19] on lower limb clinical ricket in Cox's Bazaar, a costal district of Bangladesh. As the ages' increase in groups, the prevalence of genu varum decreases; which agrees with the research conducted by Pfitzner et al., [17] in Nigeria, that the resolution of genu varum usually occurs with growth and do not require orthopedic intervention except in extreme cases.

The $4.3 \%$ prevalence of genu varum in 6-10 years old children in Urhobo communities in Delta state can be said to be relatively low when compared to the $7.9 \%$ prevalence of genu varum in Iranian primary school children [20]; $9.2 \%$ prevalence of rickets or genu varum in 6-35 months aged children in 48 ethnic group in Nigeria [17], and $14.9 \%$ prevalence in sub-urban and rural communities in Sahel savanna in Nigeria [18]. However, the $4.3 \%$ prevalence is relatively high when compared to the $1.6 \%$ prevalence of children in the city of Manchester [16] and 0.007 or less than $1 \%$ prevalence in the population of children in United States [15].

In this work, the prevalence of genu varum in younger children (6 years) compared to older children (10 years) in Urhobo communities in Delta state may be ascribed to inability of these younger children to feed themselves properly when left alone to eat during meals and often left indoors by the older children when their parents had gone to fend for the family.

Also, some of these children Inherit genu varum from their parents. The prevalence of this deformity In Urhobo communities is low when compared with the overall prevalence in Nigeria. The Urhobos live in the riverine area of the country and their occupation are mainly farming, hunting and fishing with their meals consisting mainly of products from their farm, hunting and fishing occupation. Seafood are known to be very rich in protein and calcium.

\section{CONCLUSION}

The prevalence of this deformity (genu varum) in 6-10 years old children in Urhobo communities in Delta state has an average of 4.3\% (43 cases in 1000 sample size). $6.4 \%$ in males and 2.2 in females. The prevalence of this deformity in Urhobo community is low when compared with the overall prevalence in Nigeria.

The prevalence of this genu varum in this ethnic nationality although low can be further reduced with enlightenment and education of parents and children on the importance of balanced diet and exposure to morning sunlight.

\section{ACKNOWLEDGEMENTS}

We sincerely appreciate the entire management and staff of the Department of Surgery, Faculty of Clinical Sciences, College of Health Sciences, University of Port Harcourt, Nigeria and Department of Anatomy, University of Port Harcourt.

Conflict of Interest: We write to state that there is no conflict of interest.

Source of Funding: Self-funding.

\section{AUTHOR'S CONTRIBUTION}

We write to state that all authors have contributed significantly and that all authors are in agreement with the contents of the manuscript. 'Author A' (Peter D. Okoh) designed the study and protocol, wrote the first draft of the manuscript; reviewed the design, protocol; 'Authors B' (John N. Paul) examined the intellectual content of the manuscript, 'Authors $C$ ' (Emmanuel Tobore) did the analysis of the study and literature search. All authors read and approved the final manuscript.

\section{REFERENCES}

1. Stevens, P. M. (2019). Pediatric Genu Varum. Drugs \& Diseases: Orthopedic Surgery. Updated.

2. Ibrahima, F., Fokam, P., Nonga, B. N., \& Sosso, M. A. (2017). Proposal for classification of angular deformities of the knee in black African children. Rheumatol Orthop Med, 2(4):4-14.

3. Murphy, R. F., Pacult, M. A., Barfield, W. R., \& Mooney III, J. F. (2020). Hemiepiphyseodesis for Juvenile and Adolescent Tibia Vara Utilizing Percutaneous Transphyseal Screws. Journal of Pediatric Orthopaedics, 40(1), 17-22.

4. Woo, K., Lee, Y. S., Lee, W. Y., \& Shim, J. S. (2016). The efficacy of percutaneous lateral hemiepiphysiodesis on angular correction in idiopathic adolescent genu varum. Clinics in orthopedic surgery, 8(1), 92-98.

5. Rajabi, R., Gorjian, H., \& Tabar, S. (2015). Determination of Knee Alignment Index (Genu Valgum \& Genu Varum) in Different Age Groups for Women in Mazandaran Province. International Journal of Sport Sciences, 2(1), 1-6.

6. Shaty, W. G., \& FJMS, C. (2015). Clinical and statistical assessment of aetiological factors of genu varum in children. Thi-Qar Medical Journal, 10(2), 23-36.

7. Sadeghi, H., Shirvanipour, S., \& Mimar, R. (2017). The Comparison of Vertical Ground Reaction Force during Forward and Backward Walking among Professional Male Karatekas with Genu Varum and Normal Knees. Journal of Sport Biomechanics, 3(1), 37-46.

8. Catani, F., Ensini, A., Zambianchi, F., Illuminati, A., \& Matveitchouk, N. (2020, February). Robotic-arm assisted total knee arthroplasty in knees with varus deformity. In Orthopaedic Proceedings (Vol. 102, No. SUPP_1, pp. 73-73). 
The British Editorial Society of Bone \& Joint Surgery.

9. Zhang, J., Bhowmik-Stoker, M., Scholl, L., Condrey, C., Marchand, K., \& Marchand, R. (2019). Robotic Arm Assisted Total Knee Arthroplasty: Addressing 1-12 Degrees Valgus Knees. EPiC Series in Health Sciences, 3, 444447.

10. Van Gheluwe, B., Kirby, K. A., \& Hagman, F. (2005). Effects of simulated genu valgum and genu varum on ground reaction forces and subtalar joint function during gait. Journal of the American Podiatric Medical Association, 95(6), 531-541.

11. Pedersen P, Michaelsen KF, Mølgaard C. Children with nutritional rickets referred to hospitals in Copenhagen during a 10- year period. Acta paediatrica. 2003 Jan;92(1):87-90.

12. Benjamin, W., \& Van Voorhees. (2006). Osteomalaca in children: vitamin D deficiency; Renal Rickets. Review provided by Verimed Health Care.

13. Connecticut Children Medical Center. (2007). Journal of Bone and Joint Surgery-British, 89(1): 57-61.

14. 14. Mahmoud Karimi-Mobarake, Alireza Kashefipour and Zahra (2003). The Prevalence of Germ Varum and Genu. Valgwn in Primary School Children in Iran. Journal of Medical Sciences, 2005; 5 (1): 52-54.
15. Davids, J. R., Blackhurst, D. W., \& Allen, J. B. (2000). Clinical evaluation of bowed legs in children. Journal of pediatric orthopedics. Part $B, 9(4), 278-284$.

16. Ashraf, S., \& Mughal, M. Z. (2002). The prevalence of rickets among non-Caucasian children. Archives of disease in childhood, 87(3), 263-264.

17. Pfitzner, M. A., Thacher, T. D., Pettifor, J. M., Zoakah, A. I., Lawson, J. O., Isichei, C. O., \& Fischer, P. R. (1998). Absence of vitamin D deficiency in young Nigerian children. The Journal of pediatrics, 133(6), 740-744.

18. Akpede, G. O., Omotara, B. A., \& Ambe, J. P. (1999). Rickets and deprivation: a Nigerian study. The journal of the Royal Society for the Promotion of Health, 119(4), 216-222.

19. Karim, F., Chowdhury, A. M. R., \& Gani, M. S. (2003). Rapid assessment of the prevalence of lower limb clinical rickets in Bangladesh. Public Health, 117(2), 135-144.

20. Karimi-Mobarake, M., Kashefipour, A., \& Yousfnejad, Z. (2005). The prevalence of genu varum and genu valgum in primary school children in Iran 2003-2004. Journal of Medical Sciences, 5(1), 52-4.

21. Brooks, W. C., \& Gross, R. H. (1995). Genu varum in children: diagnosis and treatment. JAAOS-Journal of the American Academy of Orthopaedic Surgeons, 3(6), 326-335. 